\title{
Lifelong Impact of Severe Atopic Dermatitis on Quality of Life: A Case Report
}

\author{
Arjun M. Bashyam (D) - Sohini Ganguli · Puneet Mahajan · \\ Steven R. Feldman
}

Received: January 19, 2021 / Accepted: March 18, 2021 / Published online: April 9, 2021

(C) The Author(s) 2021

\section{ABSTRACT}

Severe, uncontrolled atopic dermatitis (AD) persisting from childhood to adulthood can have enduring quality of life (QoL) impacts on daily functioning, academics, career, family and social life, and mental health. In addition, $\mathrm{AD}$ has an impact on direct and indirect healthcare resource utilization. Several studies have attempted to quantify the quality of life and direct/indirect economic burden of AD. However, these estimates may not capture the more intangible disease-related burden and associated economic burden. This was a qualitative case report that aimed to investigate the full lifetime impact of severe, uncontrolled $\mathrm{AD}$ on all aspects of a single patient's life. This case report emphasizes the enormous cumulative lifetime impact of severe, uncontrolled $\mathrm{AD}$ and where the qualitative indirect impact may not be fully captured. After obtaining consent, a patient, diagnosed with severe $\mathrm{AD}$ since birth, was asked close- and open-ended questions about AD history, direct and indirect healthcare resource utilization, and impact of $\mathrm{AD}$ on work, home, family, social life, daily functioning, and mental health over the course of her lifetime. Our patient attributed her severe, uncontrolled AD since birth to causing poor sleep quality, depression, anxiety, and difficulty with social connections and to her choosing an alternative, less physically demanding career. Early effects on sleep and school performance, along with impact on social connections, likely contribute to weaker career opportunities and further social isolation with age.

Keywords: Atopic dermatitis; Burden of disease; Case report; Mental health; Productivity; Psychosocial; Quality of life

\footnotetext{
A. M. Bashyam ( $₫) \cdot$ S. R. Feldman

Department of Dermatology, Wake Forest School of Medicine, Center for Dermatology Research,

Winston-Salem, NC, USA

e-mail: abashyam@wakehealth.edu

S. Ganguli · P. Mahajan

Sanofi Genzyme, Cambridge, MA, USA
} 


\section{Key Summary Points}

This qualitative case report investigated the lifetime impact of severe, uncontrolled $\mathrm{AD}$ on all aspects of a single patient's life.

A patient, diagnosed with severe AD since birth, was asked close- and open-ended questions about AD history, direct and indirect healthcare resource utilization, and impact of AD on work, home, family, social life, daily functioning, and mental health over the course of her lifetime.

Our patient attributed her severe, uncontrolled $\mathrm{AD}$ since birth to causing poor sleep quality, depression, anxiety, and difficulty with social connections and to her choosing an alternative, less physically demanding career.

Early effects on sleep and school performance, along with impact on social connections, likely contribute to weaker career opportunities and further social isolation with age.

\section{DIGITAL FEATURES}

This article is published with digital features, including a summary slide, to facilitate understanding of the article. To view digital features for this article go to https://doi.org/10.6084/ m9.figshare.14224259.

\section{INTRODUCTION}

Atopic dermatitis (AD) results in significant patient-level and societal burden [1]. Severe, uncontrolled AD persisting from childhood to adulthood can have enduring quality of life (QoL) impacts on daily functioning, academics, career, family and social life, and mental health. In addition, $\mathrm{AD}$ has an impact on direct and indirect healthcare resource utilization [1]. Patients with inadequately controlled AD have decreased overall QoL and work productivity; increased depression, anxiety, and sleep impairment; and increased healthcare utilization compared to patients with controlled $\mathrm{AD}$ and patients without AD [2]. Although it is difficult to quantify the full economic burden of $\mathrm{AD}$, the indirect costs of atopic diseases can exceed direct costs [3]. Several studies have attempted to quantify the QoL and direct/indirect economic burden of $\mathrm{AD}$ [3-6]. However, these estimates may not capture the more intangible disease-related burden and associated economic burden.

This case report emphasizes the enormous cumulative lifetime impact of severe, uncontrolled $\mathrm{AD}$ and where the qualitative indirect impact may not be fully captured. The patient has provided consent for the publication of this article. Written informed consent for publication of the patient's clinical details was obtained and a copy of the consent form is available for review by the editor.

\section{CASE REPORT}

This was a qualitative study that aimed to investigate the full lifetime impact of severe, uncontrolled $\mathrm{AD}$ on all aspects of a single patient's life. A comprehensive, semi-structured interview guide was developed and based on review of the existing QoL and direct/indirect impact literature. After we obtained consent, a patient, diagnosed with severe AD since birth, was asked close- and open-ended questions about AD history, direct and indirect healthcare resource utilization, and impact of $\mathrm{AD}$ on work, home, family, social life, daily functioning, and mental health over the course of her lifetime. Life events specific to the subject (school, after graduation from school, getting married, having children) were used as anchor points and memory cues to capture details of AD's impact over a lifetime. The Wake Forest School of Medicine Institutional Review Board granted approval of the study. 


\section{Childhood}

Our patient, a Caucasian woman, now age 50, was diagnosed with AD as an infant. In infancy, she had moderate involvement of her arms and face, which was primarily treated with topical corticosteroids. However, during elementary school, our patient's AD worsened with more lower extremity involvement and increased frequency of flares. Additionally, she developed concomitant severe asthma.

The patient's mother primarily took care of her as a child. Her mother, a waitress, spent more than one additional hour per day, on top of regular childcare duties, taking care of our patient because of her medical conditions. The patient's mother often had to take time off work to take care of her when she had a flare and missed school or had to go to a doctor's appointment. Our patient believes that because of her $\mathrm{AD}$, her mother's career choice was impacted since her mother was unable to take other types of jobs that did not allow her flexible time off.

\section{School}

At age 15, the AD worsened even further with face and full-body involvement, including fissuring of the hands. The patient was admitted to the hospital more than five times during childhood for acute AD and asthma exacerbations. She estimates missing more than 20 days of school each year. Even when at school, she missed many hours at the school nurse's office.

During school, she always wore full-length shirts and pants to prevent others from seeing her skin. She often felt self-conscious and embarrassed about the appearance of her skin because others would stare. She recalls being asked by classmates if "it" was contagious. Other children would often avoid her or talk behind her back. Additionally, our patient felt even more isolated as she was often unable to participate in physical activity because of $\mathrm{AD}$ and asthma. She found it difficult to make friends and felt anxious at a young age.

The pain, pruritus, and difficulty with social relationships affected her productivity at school. She spent a lot of energy trying not to be noticed. She feels that she would have done better in school if not for the AD, but this did not stop her from continuing her education. She initially wanted to study nursing; however, she felt that she could not meet the physical requirements for the career, so she instead pursued nutrition since she felt it was a less physically demanding career.

\section{Adulthood}

Her AD's severity seemed to subside slightly in her mid-20s but worsened again in her early 30s-she had had constant, severe AD since then. She has been treated with systemic immunosuppressants at various points. Now, with more than $50 \%$ body surface area involvement, $\mathrm{AD}$ affects her face (worse under the eyes), chest, back, abdomen, upper thighs, forearms, hands, and lower legs. On the face, trunk, and extremities, there are scattered eczematous plaques with lichenification and scarring. On her hands, there is fissuring. She has corticosteroid-induced striae on the abdomen and upper thighs. Her skin appearance has become worse over time with scarring, hyperpigmentation, and hypopigmentation.

The two areas that cause her the most difficulty are the hands and face. Hand involvement makes it painful and difficult to do everyday things such as cleaning her home. Face involvement makes her self-conscious and embarrassed about her appearance. Her pruritus is the most bothersome symptom because it affects her at all times of the day, even when alone, and causes difficulty concentrating on tasks. She attributes pruritus as the cause of her poor quality of sleep and insomnia.

Every 4-6 months, she has a flare where she has a worsening of symptoms with a combination of superinfection, pruritus, or pain. These flares often prevent her from going to work or doing housework. She is constantly worried and anxious about when the next flare will come. It is difficult for her to make longer-term plans with the uncertainty. 


\section{Social and Daily Functioning}

Our patient tries to avoid leaving her house as much as possible, other than for work and necessary chores. She always wears long-sleeved shirts/pants, socks, and shoes as she is selfconscious about others seeing her skin. She finds it impossible to conceal her facial lesions. She does not have many close friends and has trouble meeting new people. AD has led to a lot of social anxiety, which she believes impacted her relationships. Health was a point of stress in both of her marriages. Our patient currently lives with her adult daughter after two marriages that ended in divorce. Now, she prefers not to leave home unless she has to and spends most of her free time reading.

Our patient spends approximately $1 \mathrm{~h}$ per day directly taking care of her $\mathrm{AD}$, including applying topicals, taking pills, and shopping for supplies. She only wears cotton and always wears long sleeves, long pants, socks, and shoes, even in hot weather, to prevent skin from being seen by others. She has poor sleep and feels that she only gets $3-4 \mathrm{~h}$ a night. She has difficulty both falling asleep and staying asleep due to worse pruritus and anxiety at night. Her AD affects her home duties as well. She feels that her AD slows her down-she must take breaks when doing anything that requires too much movement (vacuuming, carrying things).

During school, she could not play sports or exercise much because of $\mathrm{AD}$ and asthma. When she started sweating or was in the heat, her skin would itch. She was always worried about the next infection or asthma exacerbation. This continues now, and she finds it difficult to control her weight as she cannot exercise though she worries some of the weight is because of the chronic corticosteroids. She tries to stay away from activities that cause her to overheat or sweat because that can cause her to break out. Her obesity may also be partly due to chronic corticosteroid use.

\section{Comorbidities}

Our patient has had a long history of complications of her $\mathrm{AD}$, concomitant asthma, and side effects of chronic corticosteroid use. She often needs pulse oral corticosteroids for exacerbations and has been to the emergency department (ED) and hospitalized many times. She has been on and off oral prednisone for several years for her asthma, as she has had difficulty controlling her asthma with inhalers. Our patient already developed cataracts in both her eyes and had cataract surgery likely due to chronic corticosteroid use from her asthma and AD.

\section{Mental Health}

She has long-standing anxiety and depression since childhood, which she attributes to her AD and appearance. Sometimes she feels agitation with anger about her $\mathrm{AD}$ and questions why this happened to her. It affects every aspect of her life. She has seen a psychiatrist in the past and has been managing generalized anxiety disorder and depression with medication prescribed through her primary care physician.

\section{Work}

After completing high school, the patient studied nutrition in college and completed an additional year of training as a dietician. She went into this field because of her $\mathrm{AD}$ and her desire to work in healthcare. Her career as a dietician allowed her to work in healthcare but not have the stress or difficult schedule her original career preference, nursing, would have had. Since finishing training, she has worked as a dietician at nursing homes and long-term care facilities. However, she has missed a lot of work because of $\mathrm{AD}$-for flares, office visits, and hospitalizations. Additionally, she must call off from work at least one day a month because of her uncontrolled AD.

Luckily, her employer is very flexible and allows her the freedom to work part-time and also maintain her health insurance. Her income dropped from approximately $\$ 50,000$ to $\$ 34,000$ when she went part-time because of her AD. She now works $30 \mathrm{~h}$ per week on average. While she does not make as much money as she 
would like, the reduced work and stress has been good for her AD and anxiety.

Pruritus and pain often distract her from work and slow her down. She finds it difficult to find work because of her skin. In the past, many employers would not hire her because of either her skin's appearance or her inability to work full-time. She has lost several jobs because of missed days from work. Previous co-workers would talk about her behind her back, and she has left several jobs as a result of this.

\section{Healthcare Economic Burden}

Our patient usually sees a dermatologist (AD) twice per year and sees her primary care physician three times per year (AD, asthma, anxiety, and depression). She estimates that she has to go to the emergency department and/or been hospitalized for AD infection or asthma exacerbation at least every 3 years on average since age 15 . From the 2010-2019 period alone, she has had 25 dermatology office visits for AD. She has commercial insurance through work. Additionally, she spends money every month at the pharmacy on medications and creams, including emollients, antihistamines, intranasal corticosteroids, eyedrops, unscented bath wash, petrolatum, and gauze bandages. She makes AD care a priority and finds ways to save money elsewhere in her budget.

\section{DISCUSSION}

Quantitative studies are very useful for understanding the cost of disease and for obtaining data that permits comparisons of impact across different diseases. The dry nature of quantitative data tends not to elicit emotional understanding of the impact. This study focused on one patient and is limited by recall bias. While this approach does not give a representative quantitative picture of the impact of atopic dermatitis, this anecdotal approach gives a deeper, clearer perspective on the potential impact that AD has across a patient's entire life.

Our patient attributed her severe, uncontrolled AD since birth to causing poor sleep quality, depression, anxiety, and difficulty with social connections and to her choosing an alternative, less physically demanding career. Severe, uncontrolled AD similar to our patient's case can have enormous QoL impacts as well as direct and indirect costs to the individual and society.

The opportunity cost of our patient's choice of dietician as an alternative career to her original desire of nursing is high over the course of a lifelong career [7]. Our patient's part-time salary compared with her previous full-time salary may provide insight into the opportunity cost of part-time status. This may capture absenteeism and presenteeism. This large discrepancy between part-time and full-time work may, in large part, be attributed to the myriad of lasting effects of her $\mathrm{AD}$ and asthma. Missing work or taking time off further compounded the effect of AD by likely not allowing more growth in our patient's career. Together these costs, over the course of lifetime, are colossal. Future studies may attempt to quantify these indirect costs of $\mathrm{AD}$ more broadly across a larger population to more fully understand the impact of severe, uncontrolled $\mathrm{AD}$. This case study captures the effects of $\mathrm{AD}$ on a single patient's life but cannot not be generalized without further study.

The impact of AD is cumulative. Early effects on sleep and school performance, along with impact on social connections, likely contribute to weaker career opportunities and further social isolation with age. While our patient exhibited considerable resilience, the cumulative effects of $\mathrm{AD}$ were still evident.

\section{ACKNOWLEDGEMENTS}

The authors would like to thank the patient for her involvement in the study. The authors thank Mandeep Kaur (Sanofi) for her contributions to the study.

Authorship. All named authors meet the International Committee of Medical Journal Editors (ICMJE) criteria for authorship for this article, take responsibility for the integrity of the work as a whole, and have given their approval for this version to be published. 
Data Availability. All data generated or analyzed during this study are included in this published article.

Funding. This study and the journal's Rapid Service Fee was funded by Sanofi and Regeneron Pharmaceuticals, Inc.

Disclosures. Steven Feldman has received research, speaking and/or consulting support from a variety of companies including Galderma, GSK/Stiefel, Almirall, Leo Pharma, Boehringer Ingelheim, Mylan, Celgene, Pfizer, Valeant, Abbvie, Samsung, Janssen, Lilly, Menlo, Merck, Novartis, Regeneron, Sanofi, Novan, Qurient, National Biological Corporation, Caremark, Advance Medical, Sun Pharma, Suncare Research, Informa, UpToDate and National Psoriasis Foundation. He is founder and majority owner of www.DrScore.com and founder and part owner of Causa Research, a company dedicated to enhancing patients' adherence to treatment. Arjun Bashyam has no conflicts to disclose. Sohini Ganguli and Puneet Mahajan are former employees of and stockholders in Sanofi at the time of study.

Compliance with Ethics Guidelines. The patient has provided consent for the publication of this article. Written informed consent for publication of the patient's clinical details was obtained and a copy of the consent form is available for review by the editor.

Open Access. This article is licensed under a Creative Commons Attribution-NonCommercial 4.0 International License, which permits any non-commercial use, sharing, adaptation, distribution and reproduction in any medium or format, as long as you give appropriate credit to the original author(s) and the source, provide a link to the Creative Commons licence, and indicate if changes were made. The images or other third party material in this article are included in the article's Creative Commons licence, unless indicated otherwise in a credit line to the material. If material is not included in the article's Creative Commons licence and your intended use is not permitted by statutory regulation or exceeds the permitted use, you will need to obtain permission directly from the copyright holder. To view a copy of this licence, visit http:// creativecommons.org/licenses/by-nc/4.0/.

\section{REFERENCES}

1. Drucker AM, Wang AR, Li WQ, Sevetson E, Block JK, Qureshi AA. The burden of atopic dermatitis: summary of a report for the National Eczema Association. J Invest Dermatol. 2017;137(1):26-30. https://doi. org/10.1016/j.jid.2016.07.012.

2. Eckert L, Gupta S, Gadkari A, Mahajan P, Gelfand JM. Burden of illness in adults with atopic dermatitis: analysis of National Health and Wellness Survey data from France, Germany, Italy, Spain, and the United Kingdom. J Am Acad Dermatol. 2019;81(1):187-95. https://doi.org/10.1016/j.jaad.2019.03.037.

3. Strozek J, Samolinski BK, Klak A, et al. The indirect costs of allergic diseases. Int J Occup Med Environ Health. 2019;32(3):281-90. https://doi.org/10.13075/ ijomeh.1896.01275.

4. Sandhu JK, Salame N, Ehsani-Chimeh N, Armstrong AW. Economic burden of cutaneous infections in children and adults with atopic dermatitis. Pediatr Dermatol. 2019;36(3):303-10. https://doi.org/10. 1111/pde.13828.

5. Olsson M, Bajpai R, Wee LWY, et al. The cost of childhood atopic dermatitis in a multi-ethnic Asian population: a cost-of-illness study. $\mathrm{Br} \mathrm{J}$ Dermatol. 2019. https://doi.org/10.1111/bjd.18442.

6. Ariens LFM, van Nimwegen KJM, Shams M, et al. Economic burden of adult patients with moderate to severe atopic dermatitis indicated for systemic treatment. Acta Derm Venereol. 2019;99(9):762-8. https:// doi.org/10.2340/00015555-3212.

7. May 2018 State Occupational Employment and Wage Estimates: North Carolina. US Bureau of Labor Statistics. 2020. https://www.bls.gov/oes/2018/may/oes_ nc.htm\#31-0000. Accessed 9 Aug 2020. 